\title{
Water Security - science and management challenges
}

\author{
HOWARD S. WHEATER
}

Global Institute for Water Security, University of Saskatchewan, National Hydrology Research Centre, 11 Innovation Boulevard, Saskatoon, SK, S7N 3H5, Canada howard.wheater@usask.ca

\begin{abstract}
This paper briefly reviews the contemporary issues of Water Security, noting that current and prospective pressures represent major challenges for society. It is argued that, given the complex interdependencies and multi-faceted nature of these challenges, new trans-disciplinary science is needed to support the development of science-based policy and management. The effects of human society on land and water are now large and extensive. Hence we conclude that: (a) the management of water involves the management of a complex human-natural system, and (b) potential impacts of the human footprint on land and water systems can influence not only water quantity and quality, but also local and regional climate. We note, however, that research to quantify impacts of human activities is, in many respects, in its infancy. The development of the science base requires a trans-disciplinary place-based focus that must include the natural sciences, social sciences and engineering, and address management challenges at scales that range from local to large river basin scale, and may include trans-boundary issues. Large basin scale studies can provide the focus to address these science and management challenges, including the feedbacks associated with man's impact from land and water management on regional climate systems.
\end{abstract}

\section{THE CHALLENGES OF WATER SECURITY}

'Water Security' is a phrase that is increasingly being used to represent the multiple challenges associated with 21st century water management (Cook and Bakker 2012). It has been defined as the "sustainable use and protection of water resources, safeguarding access to water functions and services for humans and the environment, and protection against water-related hazards (flood and drought)" (Wheater and Gober 2013).

Water Security embodies a complex, multi-dimensional and interdependent set of issues. With increasing pressures on water resources, there is heightened competition for the uses of water at local, regional and international scales, both between sectors of the economy and between upstream and downstream jurisdictions. These uses are diverse. They include basic societal needs such as drinking water supply, irrigation, hydropower and industrial uses. Water quality is a further key dimension of water use. Rivers are used to receive, transport and dilute wastes, and intensification of human activities is putting increasing pressure on the quality of both surface waters and groundwater, with consequences for water resource availability for various uses. Water-related ecosystem functions, with their dependence on water quantity (and its temporal variability) and water quality, represent a further water 'use' and a critical dimension of Water Security.

It can be noted that human activities are changing land use and land management, and changing the quantity and quality of surface water and groundwater resources. These reflect physical changes to the environment, but are strongly influenced by societal needs and priorities. For example, environmental flows are often a major factor in the competing allocation of water resources, but are determined by the societal context and are likely to change as societies develop. In the USA, development of the West treated water as a commodity; in contrast, the European Union's Water Framework Directive has placed the protection of ecological quality as a high priority for water management (European Commission 2000).

While resource allocation and competing needs represent one set of Water Security challenges, a second major focus for Water Security is on extreme events. Flooding remains globally one of the most dangerous and damaging natural hazards, and with increasing pressures of population and development, the associated risks are increasing (UNESCO 2012). Flooding is often seen simply as the response of a natural system to an extreme weather event, but the reality is that human activity changes the environment in multiple ways. Thus flood risk, and flood risk management, is intimately linked to land and water management. Land management effects include urbanisation (Wheater 2006), as well as agricultural development and intensification 
(Wheater and Evans 2009), and land-use policy (or lack of policy) has been a key factor in permitting urban developments in areas of risk. Water management for much of the 20th century has disconnected flood plains from river channels, to provide local protection for urban development or agriculture, with a consequent increase in flood hazard downstream (Wheater 2006). Thus, flood risk results from complex interactions between extreme events, human changes to the natural environment, human perceptions and responses to risk, and the capacity of human institutions to reduce and manage risk.

Similarly, drought has multiple physical and societal dimensions. Clearly a lack of precipitation will lead to pressures on water resources and agriculture, and effects can be severe, depending on the resilience of the local society and population. Tensions between competing water uses will be exacerbated, not least between human uses and environmental flows (Grafton et al. 2011). Drought can constrain the multiple societal uses of water noted above, including energy production, at local and regional levels. However, given the global nature of food markets, agricultural drought can have wider-ranging repercussions. For example, events such as the 2010 Russian heat-wave, which affected global food prices, were reported to be one aspect of the social unrest that lead to the Arab Spring (Economist 2012).

A final dimension to Water Security is the need to understand and manage the above challenges in the context of environmental change. The anthropogenic effects of land and water management have been noted above - to these we need to add the effects of climate variability and change. Climate is itself a multi-faceted driver of hydrological change. Changing patterns of precipitation and temperature will change river flows and groundwater recharge. But important feedbacks exist - some known, some as yet unknown. To take one example of biological feedbacks, one of the largest changes to land use in western Canada has been the death of forests due to bark-beetle infestation - in part a function of warmer winters. More generally, water futures will also depend on anthropogenic responses to climate change in the form of changes to land and water management (not to mention emissions policy).

It can be concluded that Water Security has multiple and highly interconnected dimensions, that each of these involves complex interactions between human society and the natural environment, and that to address them requires holistic assessment and the need to tackle significant challenges of science, policy and governance. It is evident from the above that Water Security has significant human dimensions, and the term socio-hydrology has been adopted to recognize these, with varying definitions. Sivapalan et al. (2012) have used the term sociohydrology to describe the study of the "co-evolution of human-natural coupled systems". Gober and Wheater (2014) concur, but take a somewhat broader perspective, including organizational and institutional flexibility for handling uncertainty and change, social capital and adaptive governance, and the need for engagement with stakeholders in knowledge exchange. Thus, as noted by Wheater and Gober (2014), the interface between the research, practitioner and stakeholder communities is increasingly seen as important to the perception and management of Water Security.

\section{TOWARDS A NEW SCIENCE AGENDA}

With increasing pressures on the water environment, there is an increasing need for advances in disciplinary science to underpin our capability to understand and model the natural environment. For example, much remains to be known of the transport of water (and solutes) through landscapes, the feedbacks from land to atmosphere of water, energy and carbon fluxes, and the response of terrestrial and aquatic ecosystems to natural variability. And while much work has focused on humid, temperate climates, other environments have their own requirements and challenges. In cold regions, for example, energy is a dominant control on water stores and fluxes, and local features, such as blowing snow, can have a dominant effect on water redistribution in the landscape and the water balance (MacDonald et al. 2009). And in arid regions, where a single day's convective rainfall may exceed the annual average precipitation, characterisation of spatial rainfall is highly problematic, and the dominant role of channel infiltration means that an observed 
flow gives no clear signal of upstream flows (Wheater 2010). Such processes raise major challenges for process characterisation and modelling (McIntyre et al. 2007).

The continuation of disciplinary research, while absolutely needed, can perhaps be described as 'business as usual' for the research community. However, given the nature and the magnitude of the local, regional and global challenges outlined above, we argue that there are four critical dimensions that require a new paradigm for research:

(a) The effects of the Anthropocene on the water environment are pervasive and poorly understood - study of the hydrological effects of the Anthropocene is in its infancy and is a strategic priority.

The land is changing, through urbanisation and agricultural intensification; rivers, wetlands and groundwater are changing in quantity and quality due to land management change and water management; climate is changing globally, due to anthropogenic emissions, but also locally, due to changing land and water use. While much has been written about the effects of climate non-stationarity, following Milly et al. (2008), much less attention has been given to other effects of the Anthropocene on changing land use and land management, and those effects on changing climate. Non-stationarity of environmental systems is, however, general and widespread, with major implications for contemporary hydrological practice and water management. Many of the effects are poorly understood and poorly modelled due to lack of knowledge and/or relevant data. For example, even in densely populated and gauged environments, while forestry has been well studied, effects of agricultural intensification remain quite uncertain (Wheater and Evans 2009). For large-scale, sparsely-gauged environments such as the Canadian prairies, effects of the 'breaking of the land' in the 20th century have not been characterised, and modern changes in land management, such as zero till, which affect the local water balance and nutrient exports, have had little attention from the hydrological community. And while effects of urbanisation are well known in principle, their hydrological effects are determined by local infrastructure and local management, so that characterisation of impacts at the basin scale remains challenging. Similarly, water management systems are often highly complex, and subject to multiple constraints and operational controls. While these may be known at a local level, their representation at regional and global scales remains challenging (Nazemi and Wheater 2015a,b). Effects of land and water management are therefore complex and depend very much on the local context. Hitherto, attention to these effects has primarily been focused on the aquatic and terrestrial environments; however, the extensive nature of changes is such that increasing evidence of feedbacks to local climate are being reported. Effects on climate of the regional-scale changes associated with large-scale irrigation and loss of flows to the Aral Sea have been reported by Destouni et al. (2010). More subtle effects of irrigation and vegetation change on precipitation generation have also been reported; see for example applications in California by Lo and Famiglietti (2013) and Sorooshian et al. (2011).

(b) Effects of human activities on the water environment and the management challenges of Water Security are multi-faceted and subject to complex interdependencies - new transdisciplinary science is needed.

In the discussion above, we noted the wide-ranging effects of human activities on the water environment, affecting the quantity and quality of surface and groundwater resources, aquatic ecosystems, and flood hazard, and with potential feedbacks to climate. To understand the Anthropocene therefore requires a holistic approach, integrating knowledge across multiple disciplines. This includes the natural sciences and engineering, but given that the Anthropocene is, by definition, a human-natural system, this must also include the social sciences. From a management perspective, while there has been much discussion of the Water-Energy-Food Nexus, this is to simplify the operational realities faced by most water managers. A single reservoir may have conflicting requirements for long-term storage for irrigation supply, short-term management of storage for flood risk reduction, the need to 
maximise downstream flows for hydropower generation, and various local and downstream constraints for habitat protection and amenity use. Conflicts concerning environmental flows go beyond tensions between allocations for human water use and water for the environment. Concerning flood risk, for example, it is desirable for natural wetlands to experience a diversity of flows and maintain a realistic flood regime, but this may threaten local riparian communities and indigenous people. We also note that water quantity and water quality have complex operational interactions. For example, there may be a need to maintain flows to dilute effluents below concentration limit values in receiving waters. And while multiple sectors of the economy depend on water, agriculture has a particularly important role; farmers are managers of land and water, and while agricultural management can affect downstream flows and water quality, land management can also be used to mitigate effects of water quality and flooding. We also note that agriculture can place operation requirements on water quality; increasingly constraints placed on farmers by the supply chain require certification of the quality of water used for irrigation (Council of Canadian Academies 2013).

We conclude that both understanding the Anthropocene and providing decision support for planning and management requires water systems to be considered as a whole in their full complexity. There is a need for a new paradigm of trans-disciplinary science to address both the science and the management challenges. Water quantity, water quality and ecology are evidently interdependent and integration across the natural sciences is required. However, recognising the discussion in (a) above, a new science agenda must recognise the role of human attitudes and activities in shaping the land and water environment. Water allocation and water management ultimately reflect social preferences and political choice, perhaps seen most obviously in decisions related to environmental flows. Key science questions for Water Security therefore include not only the challenging issues of understanding and predicting the effects of environmental change on water quantity and quality and aquatic ecosystems, but also understanding the effects of social values and societal controls on land and water management. To meet the challenges of Water Security, integration of the social sciences with the natural sciences and engineering is required.

(c) The challenges of Water Security management in the Anthropocene require new understanding of process interactions and feedbacks across multiple scales.

It is perhaps self-evident that water management must address a range of scales, including the largest scale of the systems to be managed, i.e. whole river basins and groundwater aquifers, and we note that that may involve multiple jurisdictions, with international implications in some cases. Similarly, the needs for underlying science also cross multiple scales. We noted above that effects of land management can be subtle and dependent on the local environmental context. For example, particular agricultural beneficial management practices may be advantageous in one environment and counter-productive in another and, as discussed above, impacts of urban land management often depend on local infrastructure. We therefore need to understand local effects and their larger-scale implications for management. But in fact the need to address process representation across multiple scales is generic, both for natural environmental processes and anthropogenic effects. For example, mountain hydrology is determined by complex interactions between topography, radiation, temperature and air flows that are strongly affected by local topographic detail (Marsh et al. 2012), yet emergent properties must be identified for large-scale application. Two issues arise. Firstly, the effects of the Anthropocene are now sufficiently extensive that significant land-atmosphere feedbacks can arise from large-scale changes to land and water management (as noted in (a) above). This requires new understanding of feedbacks at the scales of influence for weather systems. Secondly, with the resolution of weather and climate models rapidly increasing at regional and global scales (e.g. $2.5 \mathrm{~km}$ weather modelling was implemented nationally in Canada in 2014), there are significant unanswered challenges for hydrologists concerning the appropriate scale of parameterisations for large-scale application (see, e.g. Wood et al. 2011, Beven and Cloke 2012). Hence, new understanding of interactions and feedbacks is needed 
across multiple scales, and these include the large scales appropriate to the world's major river basins, and at which land and water management may have feedbacks to climate systems.

(d) Stakeholder engagement is a necessity, not an option.

To address the societal challenges of Water Security, a new paradigm for interactions between the science and user communities is needed. Clearly, translation of scientific understanding into useful information for policy and management is essential. However, it is equally important that the science community addresses the issues of relevance to the management of Water Security, and these are not best defined by the science community. And in this context, new approaches will be needed to develop appropriate policy and governance in the face of highly uncertain water futures, including vulnerability analysis, adaptive management and no regret solutions (Nazemi and Wheater 2014). In addition, local stakeholders are an important knowledge base; for example indigenous and other rural communities have a wealth of traditional knowledge, and farmers will have a depth of understanding of their land that is often multi-generational and will generally exceed that of a research scientist. More generally, engagement with stakeholders, including water managers, local non-governmental organisations and the public in general, is necessary to develop an informed and aware public. Essentially the major challenges of Water Security lie with governance and the need to make hard decisions - in any democratic governance system, these decisions will reflect public opinion and societal attitudes to water.

In summary, we conclude that:

(a) study of the hydrological effects of the Anthropocene is in its infancy and is a strategic priority;

(b) new trans-disciplinary science is needed;

(c) new understanding of process interactions and feedbacks is needed across multiple scales; and

(d) a new paradigm is required for scientists to engage with the full range of stakeholder communities.

How does the research community move the science agenda forward to address these issues? To engender trans-disciplinary working requires inter-disciplinary focus on common problems and common places. And to address the management challenges of Water Security, we must work at multiple scales, including the scales of large river basins and whole groundwater systems. And research at these large scales is needed to address the interactions and feedbacks associated with the large footprint of the Anthropocene.

We conclude that this requires large and high-profile basin-scale science programmes that can address critical societal needs and support the development of the new trans-disciplinary science necessary to underpin this. This requires national support and can be facilitated by global programmes. For example, the World Climate Research Programme's Global Energy and Water Exchanges (GEWEX) project includes a global network of Regional Hydroclimate Projects (RHPs). These are designed to address GEWEX priorities related to large-scale science, but draw on local and regional funding sources and commonly address linkage to stakeholder needs and concerns.

\section{THE SASKATCHEWAN RIVER BASIN AS A REGIONAL HYDROCLIMATE PROJECT}

These issues are illustrated by drawing on a case study of the $406000 \mathrm{~km}^{2}$ Saskatchewan River Basin (SaskRB) in western Canada (Fig. 1). With one of the world's more extreme climates, it embodies many of the challenges of Water Security faced worldwide and includes environments of global significance, including the Rocky Mountains (source of the major rivers in western Canada), the Boreal Forest (representing 30\% of Canada's land area) and the Prairies (home to $80 \%$ of Canada's agriculture). Management concerns include: provision of water resources to more than three million inhabitants, including rural and indigenous communities; balancing competing needs for water between different uses, such as urban centres, industry, agriculture, 


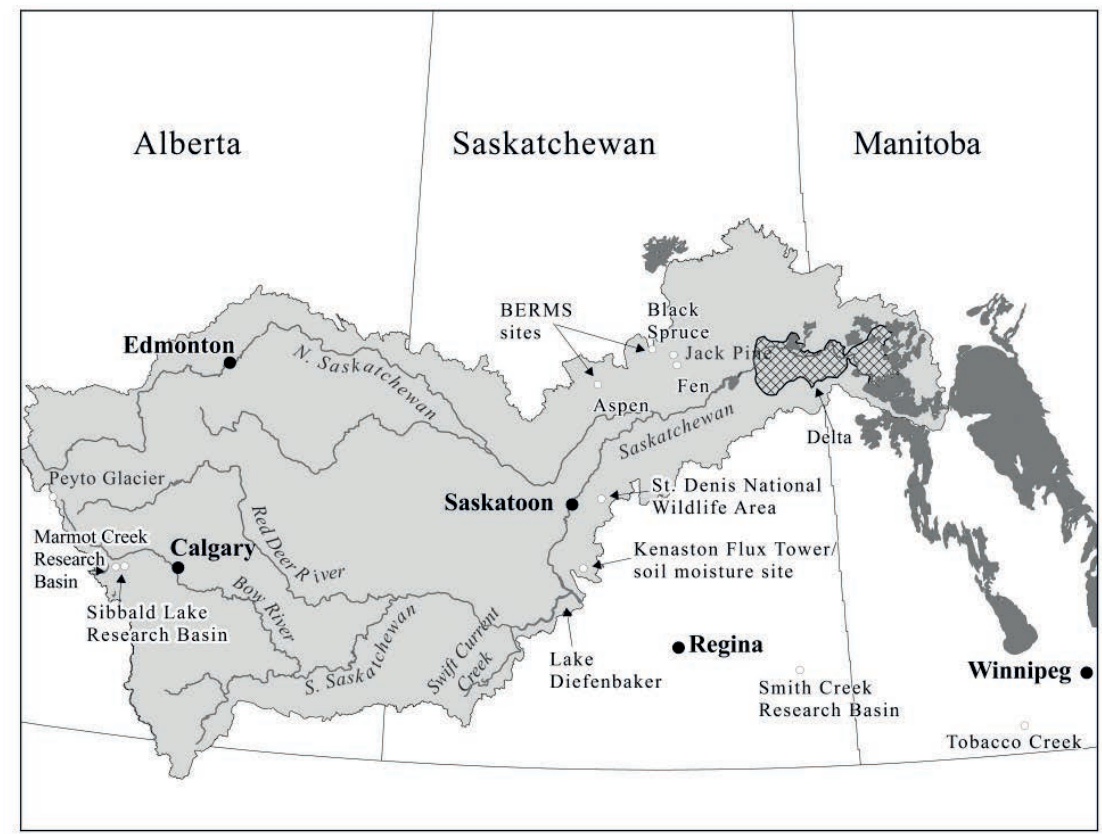

Fig. 1 Saskatchewan River Basin (SaskRB) and research sites.

hydropower and environmental flows; issues of water allocation between upstream and downstream users in the three prairie provinces; managing the risks of flood and droughts; and assessing water quality impacts of discharges from major cities and intensive agricultural production. Superimposed on these issues is the need to understand and manage uncertain water futures, including effects of economic growth and environmental change, in a highly fragmented water governance environment.

The SaskRB project is currently the only active RHP in North America. It focuses research at intensively monitored sites and small watersheds to improve understanding of hydro-ecological processes and the impacts of climate and land-use change, in conjunction with development of improved fine-scale models (Janzen and Westbrook 2011, Shook and Pomeroy 2011, Barr et al. 2012, Pomeroy et al. 2012, Menard et al. 2014, North et al. 2014, Reba et al. 2014). To understand large-scale effects on river flows and quality, land-atmosphere feedbacks, and regional climate, integrated monitoring, modelling and analysis is being developed at the large basin scale (Chun et al. 2013, Asong et al. 2015, Khaliq et al. 2015). And to support water management, new tools are being developed for operational management, and scenario and risk-based planning that can be implemented across multiple scales and multiple jurisdictions (Hassanzadeh et al. 2014, Nazemi and Wheater 2014). Socio-hydrology research includes research into attitudes and values related to Water Security, engagement of local communities in field-based research, study of the impacts of water management on livelihoods of First Nations communities, development of modelling and decision support tools to support interactive modelling of water futures for engagement with water managers and other stakeholders, and outreach activities that range from work with schools to an interactive theatre production (Gober and Wheater 2014, Gober et al. 2014).

\section{CONCLUSIONS}

We argue that the scope and magnitude of the societal challenges of Water Security are unprecedented, and that a new approach to provide the underpinning science for Water Security management is urgently needed by the global community. It is suggested that the SaskRB Regional Hydroclimate Project is an example of the type of large-scale observatory that is required to support the management of Water Security. It addresses the impacts of human activities on water quantity and quality, aquatic ecosystems and climate, and the context of rapid economic 
growth and climate change, while delivering appropriate management tools for water futures for a large trans-boundary basin. Such a place-based focus supports the new integration of the natural sciences, engineering and the social sciences that is needed to meet the challenges of managing what is a human-natural system, and the emerging field of socio-hydrology provides a vehicle for addressing human impacts on the hydrological cycle, the need for translation of science into useful information for policy and governance, the challenges of managing emergent systems that are transitioning to new states of behaviour, critical thresholds and tipping points, and the need to facilitate communication and engagement with a wide range of stakeholders. This is a challenging agenda, but, encouragingly, one which is increasingly being recognised and pursued by the international community.

\section{REFERENCES}

Asong, Z.E., Khaliq, N. and Wheater, H.S. (2015) Regionalization of precipitation characteristics in the Canadian Prairie Provinces using large-scale atmospheric covariates and geophysical attributes. Stochastic Environmental Research and Risk Assessment 29,875-892, doi:10.1007/s00477-014-0918-z.

Barr, A., et al. (2012) Energy balance closure at the BERMS flux towers in relation to the water balance of the White Gull Creek watershed 1999-2009. Agricultural and Forest Meteorology 153, 3-13, doi:10.1016/j.agrformet.2011.05.017.

Beven, K.J. and Cloke, H.L. (2012) Comment on: "Hyperresolution global land surface modeling: Meeting a grand challenge for monitoring Earth's terrestrial water" by Eric F. Wood et al., Water Resources Research 48(1), ARTN W01801.

Chun, K.P., et al. (2013) Precipitation downscaling in Canadian Prairie Provinces using LARS-WG and GLM approaches. Canadian Water Resources Journal 38(4), 311-332, http://dx.doi.org/10.1080/07011784.2013.830368.

Cook, C. and Bakker, K. (2012) Water security: Debating an emerging paradigm. Global Environmental Change 22(1), 94-102.

Council of Canadian Academies (2013) Water and Agriculture in Canada: Towards Sustainable Management of Water Resources. The Expert Panel on Sustainable Management of Water in the Agricultural Landscapes of Canada, Council of Canadian Academies, 259pp.

Destouni, G., Asokan, S.M. and Jarsjo, J. (2010) Inland hydro-climatic interaction: effects of human water use on regional climate. Geophysical Research Letters 37, L18402, doi:10.1029/2010GL044153.

Economist (2012) Food and the Arab Spring, Available from: www.economist.com/node/21550328 (accessed 20 October 2014 ).

European Commission (2000). Directive, E.U.W.F. Directive of the European parliament and of the council 2000/60/EC. Establishing a framework for community action in the field of water policy. Official Journal of the European Communities 22, 0001-0073. Available from: http://eur-lex.europa.eu/LexUriServ/LexUriServ.do?uri=CELEX:32000L0060:EN:NOT (accessed 20 October 2014).

Gober, P., et al. (2014) Divergent perspectives on water security: Bridging the policy debate. The Professional Geographer 67(1), 62-71, doi:10.1080/00330124.2014.883960.

Gober, P. and Wheater, H.S. (2014) Socio-hydrology and the science-policy interface: A case study of the Saskatchewan River Basin. Hydrology and Earth System Sciences 18, 1413-1422, doi:10.5194/hess-18-1413-2014.

Grafton, R.Q., et al. (2011) Optimal dynamic water allocation: irrigation extractions and environmental trade-offs in the Murray River, Australia. Water Resources Research 47, W00G08, doi:10.1029/2010WR009786.

Hassanzadeh, E., et al. (2014) Managing water in complex systems: An integrated water resources model for Saskatchewan, Canada. Environmental Modelling \& Software 58, 12-26, doi:10.1016/j.envsoft.2014.03.015.

Janzen, K. and Westbrook, C. (2011) Hyporheic flows along a channeled peatland: influence of beaver dams. Canadian Water Resources Journal 36(4), 331-347, doi:10.4296/cwrj3604846.

Khaliq, M.N., et al. (2015) Seasonal and extreme precipitation characteristics for the watersheds of the Canadian Prairie Provinces as simulated by the NARCCAP multi-RCM ensemble. Climate Dynamics 44, 255-277, doi:10.1007/s00382014-2235-0.

Lo, M.-H. and Famiglietti, J.S. (2013) Irrigation in California's Central Valley strengthens the Southwestern U.S. Water Cycle. Geophysical Research Letters 40(2), 301-306, doi:10.1002/frl.50108.

MacDonald, M.K., Pomeroy, J.W. and Pietroniro, A. (2009) Parameterising redistribution and sublimation of blowing snow for hydrological models: tests in a mountainous subarctic catchment. Hydrological Processes 23(18), 2570-2583, doi:10.1002/hyp. 7356 .

Marsh, C.B., Pomeroy, J.W. and Spiteri, R.J. (2012) Implications of mountain shading on calculating energy for snowmelt using unstructured triangular meshes. Hydrological Processes 26(12), 1767-1778, doi:10.1002/hyp.9329.

Wheater, H.S. (2010) Hydrological processes, groundwater recharge and surface-water/groundwater interactions in arid and semi-arid areas. In: H.S. Wheater, S. A. Mathias and X. Li, eds. Groundwater Modelling in Arid and Semi-Arid Areas. Cambridge, UK: Cambridge University Press, 5-20.

McIntyre, N., Al-Qurashi, A. and Wheater, H.S. (2007) Regression analysis of rainfall-runoff data from an arid catchment in Oman. Hydrological Sciences Journal 52(6), 1103-1118, doi:10.1623/hysj.52.6.1103.

Menard, C.B., Essery, R. and Pomeroy, J.W. (2014) Modelled sensitivity of the snow regime to topography, shrub fraction and shrub height. Hydrology and Earth System Sciences 18, 2375-2392, doi:10.5194/hess-18-2375-2014.

Milly, P.C.D. et al. (2008) Stationarity is dead: Whither water management? Science 319, 573-574, doi:10.1126/ science. 1151915

Nazemi, A. and Wheater, H.S. (2014) Assessing the vulnerability of water supply to changing streamflow conditions. Eos Transactions of the American Geophysical Union 95(32), 288, doi: 10.1002/2014EO320007.

Nazemi, A. and Wheater, H.S. (2015a) On inclusion of water resource management in Earth System models - Part 1: Problem definition and representation on water demand. Hydrology and Earth System Sciences 19, 33-61, doi:10.5194/hess-19-332015 . 
Nazemi, A. and Wheater, H.S. (2015b) On inclusion of water resource management in Earth System models - Part 2: Representation of water supply and allocation and opportunities for improved modeling. Hydrology and Earth System Sciences 19, 63-90, doi:10.5194/hess-19-63-2015.

North, R. et al. (2014) Relationship between water quality parameters and bacterial indicators in a large prairie reservoir: Lake Diefenbaker, SK, Canada. Canadian Journal of Microbiology 60(4), 243-249, doi:10.1139/cjm-2013-0694.

Pomeroy, J. et al. (2012) Sensitivity of snowmelt hydrology in Marmot Creek, Alberta, to forest cover disturbance. Hydrological Processes 26(12), 1891-1904, doi:10.1002/hyp.9248.

Reba, M.L. et al. (2014) Sensitivity of model parameterizations for simulated latent heat flux at the snow surface for complex mountain sites. Hydrological Processes 28(3), 868-881, doi:10.1002/hyp.9619.

Shook, K. and Pomeroy, J. (2011) Memory effects of depressional storage in Northern Prairie hydrology. Hydrological Processes 25(25), 3890-3898, doi:10.1002/hpy.8381.

Sivapalan, M., Savenije, H.H.G. and Blöschl, G. (2012) Socio-hydrology: A new science of people and water. Hydrological Processes 26(8), 1270-1276, doi:10.1002/hyp.8426.

Sorooshian, S., et al. (2011) How significant is the impact of irrigation on the local hydroclimate in California's Central Valley? Comparison of model results with ground and remote-sensing data. Journal of Geophysical Research 116, D06102, doi:10.1029/2010JD014775.

UNESCO (2012) The 4th edition of the UN World Water Development Report. Available from: $\mathrm{http}$ //www.unesco.org/new/en/natural-sciences/environment/water/wwap/wwdr/wwdr4-2012/ (accessed 20 October 2014).

Wheater H.S. (2006) Flood hazard and management: a UK perspective. Philosophical Transactions of the Royal Society A 364, 2135-2145, doi:10.1098/rsta.2006.1817.

Wheater, H.S. and Evans, E.P. (2009) Land use, water management and future flood risk. Land Use Policy 26S, S251-S264, doi:10.1016/j.landusepol.2009.08.019.

Wheater, H.S. and Gober, P. (2013) Water Security in the Canadian prairies: science and management challenges. Philosophical Transactions of the Royal Society A doi:10.1098/rsta.2012.0409.

Wheater, H.S. and Gober, P. (2014) Meeting the science challenges of Water Security in the Saskatchewan River Basin: a regional hydroclimate project from Western Canada. In: J.J. O’Sullivan and M. Bruen, eds. Dooge Nash International Symposium. 23-26th April, 2014, Dublin Castle, Dublin, Ireland, University College Dublin, 431-446.

Wood, E.F. et al. (2011) Hyperresolution global land surface modeling: Meeting a grand challenge for monitoring Earth's terrestrial water. Water Resources Research 7(5), doi:10.1029/2010WR010090. 